\title{
Stomatal Function and Cuticular Conductance in Whole Tissue-cultured Apple Shoots
}

\author{
K.A. Shackel, V. Novello ${ }^{1}$, and E.G. Sutter \\ Department of Pomology, University of California, Davis, CA 95616 \\ Additional index words. water transport, water stress, gas exchange, Malus pumila, rootstock M.26
}

\begin{abstract}
The relative contribution of stomatal and cuticular conductance to transpiration from whole tissue-cultured apple shoots of Malus pumila Mill. M.26 was determined with a modified steady state porometer. When shoots were exposed to $90 \% \mathrm{RH}$ and high boundary layer conductance, large $(73 \%)$ and, in some eases, rapid (2 to 3 hours) reductions in leaf conductance occurred, indicating functional stomata. Stomatal closure was also observed microscopically. A maximum estimate for the cuticular conductance of these apple leaves was 18 to $40 \mathrm{mmol} \cdot \mathrm{m}^{-2} \cdot \mathrm{s}^{-1}$, which is lower than previous estimates and close to the upper limit of naturally occurring leaf cuticular conductances. Hence, both stomatal and cuticular restrictions of water loss appear to be of importance in determining the water balance of tissue-cultured apple loots. The pathway of water transport in relation to water stress of tissue-cultured shoots is also discussed.
\end{abstract}

Lack of stomatal closure in tissue-cultured shoots has been implicated as a major cause of the desiccation that occurs when shoots are removed from in vitro conditions and placed in an unprotected environment (Brainerd and Fuchigami, 1982). Poor functioning of stomata has been attributed to abnormal micro. fibril development of guard cells (Wardle and Short, 1983) and to poor selectivity in the accumulation of $\mathrm{Na}, \mathrm{K}$, and $\mathrm{Mg}$ in guard cells while in vitro (Wardle et al., 1981).

The relative contribution of stomatal and cuticular water loss and the capacity of the stomata for normal functioning in cultured shoots remain controversial. Most of the data supporting the hypothesis that stomata in cultured shoots are nonfunctional is based on experiments with excised leaves (Brainerd et al., 1981; Fuchigami et al., 1981; Sutter and Langhans, 1982). Such experimental systems may not accurately portray conditions in vivo. Sutter (1988), using intact shoots, reported results in conflict with those discussed above. She found that stomatal conductance of intact tissue-cultured apple, cherry, and sweetgum shoots decreased when shoots were removed from in vitro conditions, but also reported rapid (within 1 to $2 \mathrm{~min}$ ) decreases in cuticular conductance. In some cases, the magnitude of the changes in stomatal and cuticular conductance were similar; hence, the separation of stomatal from cuticular function remains unclear. Another difficulty with Sutter's study was that conductance was determined at laboratory relative humidity $(37 \%$ to $45 \%$ ), which was presumably much lower than the ambient humidity under tissue culture conditions.

The objectives of this study were to determine whether stomata of intact tissue-cultured apple shoots could close in response to a moderate increase in evaporative demand in situ and to estimate the relative contribution of stomatal and cuticular conductances to the regulation of water loss from these shoots. This paper also reports the development of a porometer-based gas exchange system that is suitable for the study of stomatal functioning in tissue-cultured shoots.

Received for publication 17 Apr. 1989. The cost of publishing this paper was defrayed in part by the payment of page charges. Under postal regulations, this paper therefore must be hereby marked advertisement solely to indicate this fact.

${ }^{1}$ Istituto di Coltivazioni Aboree dell 'Università di Torino, Via Pietro Giuria, 10126 Torino, Italy. Paper no. 686.

\section{Materials and Methods}

Gas exchange system. Measurement of the gas exchange of tissue-cultured shoots was made with a modified steady state porometer (model 1600; LI-COR, Lincoln, Neb.) in a controlled-temperature room $(24 \pm 1 \mathrm{C}$, continuous fluorescent light of 30 to $35 \mu \mathrm{mol} \cdot \mathrm{s}^{-1} \cdot \mathrm{m}^{-2}$ ). The porometer was modified by replacing the leaf clamp and aperture cap with a glass adapter and by extending the leaf thermocouple wires (Fig. 1). A laptop computer (model PC-8201A; NEC, Tokyo) was programmed to operate the porometer and to collect, average, and store mea-
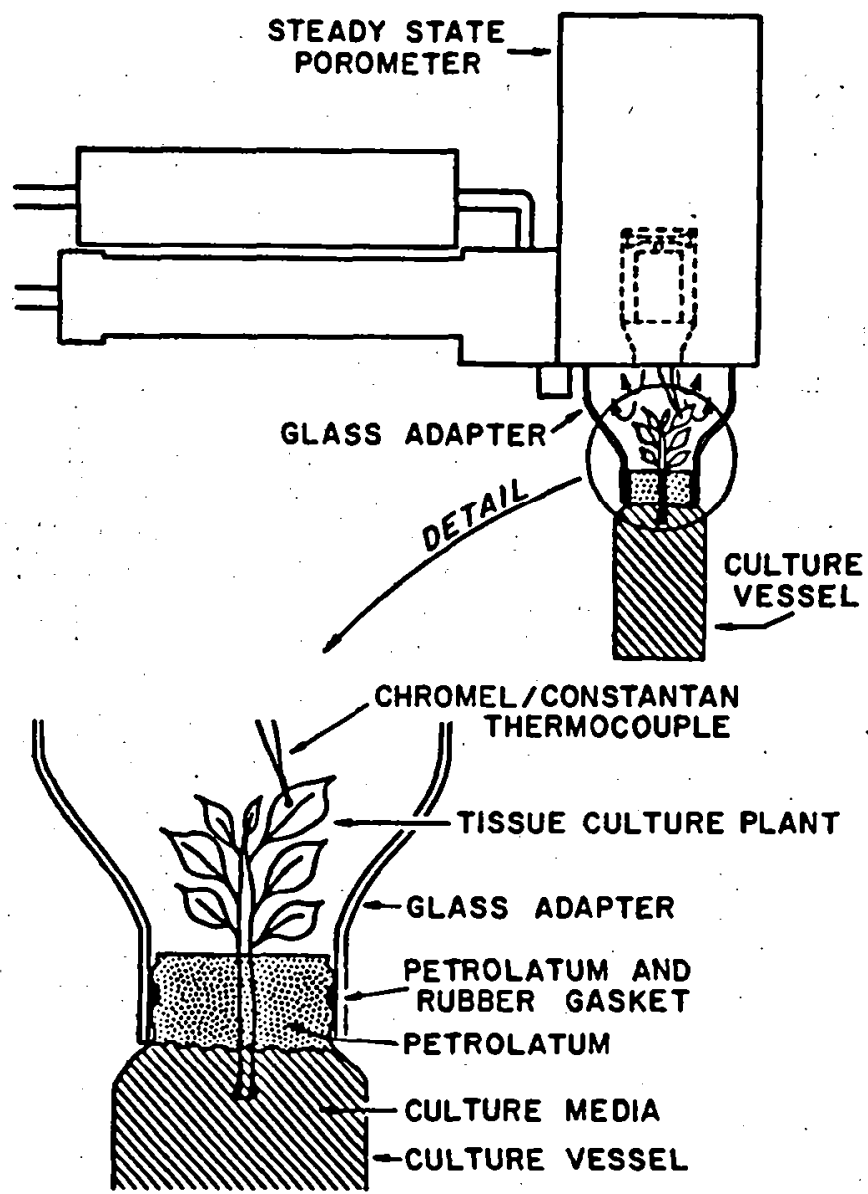

Fig. 1. Steady state porometer system used to measure the gas exchange of tissue-cultured apple shoots.

J. Amer. Soc. Hort. Sci. 115(3):468-472.

1990. 
surements for user selectable periods of time. Accuracy of the humidity sensor was verified at about weekly intervals by equilibration with a saturated $\mathrm{NaC} 1$, solution of $75.1 \% \mathrm{RH}$, as recommended by the manufacturer, and was always within $3 \% \mathrm{RH}$. A micropipette gauge (model 1600MP; LI-COR) was used to verify the accuracy of the transpiration measurements at about biweekly intervals. The gauge was substituted for the culture vessel (Fig. 1) and petrolatum was used to seal the gauge and the glass adapter. A culture vessel filled with water was used to equilibrate the system at $90 \% \mathrm{RH}$ for 1 to $2 \mathrm{hr}$ before taking measurements. After this equilibration period, good agreement was found between the water loss rate, as measured by the porometer, and that determined directly by the rate of water movement in the gauge (Fig. 2). The data for Fig. 2 were obtained immediately after installing the gauge in the system. By increasing the quantity of water in the gauge before installation, the transpiration values could also be tested after longer time intervals (up to $5 \mathrm{hr}$ ) and were always accurate to within $6 \%$. Boundary layer conductance within the glass adapter was similar to that used by the porometer for the calculation of stomatal conductance, so the conductance recorded by the porometer was only corrected for the shoot leaf area determined at the end of each experiment. Relatively small oscillations in room temperature with a 17-min period had a substantial influence on the measured values of transpiration (Fig. 2); for all experiments, the computer was programmed to collect data at 0.5 -min intervals but to store only mean values for each 17-min period.

Shoot culture and general experimental procedures. Shoots of M.26 apple rootstock were grown in vitro on agar-solidified Linsmaier-Skoog nutrient medium (Linsmaier and Skoog, 1965) to, which $1 \mathrm{mg}$ benzyladenine/liter and $162 \mathrm{mg}$ phloroglucinol/ liter were added. The cultures were incubated in a controlledenvironment chamber at $25 \mathrm{C}$, under a 16-hr photoperiod and $75 \mu \mathrm{mol} \cdot \mathrm{s}^{-1} \cdot \mathrm{m}^{-2}$ provided by cool-white fluorescent lamps, and were transferred at 4-week intervals. Individual shoots, 1.5 to $2 \mathrm{~cm}$ tall, were excised from the proliferating mass of shoots and were placed in glass scintillation vials filled with $25 \mathrm{ml}$ Linsmaier-Skoog medium. About $0.3 \mathrm{~cm}$ of the shoot was inserted into the medium. The vials were placed in a larger vessel and were allowed to continue to grow for an additional 4 days to 1 week. Water was placed in the larger vessel to just below



Fig. 2. Comparison between calculated (porometer measurement) and observed (pipette measurement) rates of water loss from a paper evaporation surface in the gas exchange system of Fig. 1. Porometer measurements were collected by a computer at 0.5 -min intervals, and pipette measurements were taken in increments of $1 \mu \mathrm{l}$ water loss. Room air temperature over time (hours : minutes) is also shown. the upper edge of the vial to increase ambient humidity and prevent drying of the shoot.

Tissue-cultured shoots were prepared for all gas exchange experiments in a humidified glove box; to prevent water evaporation from the nutrient medium, melted petrolatum was layered on the surface of the medium (Fig. 1) using a syringe and needle. Three protocols for shoot preparation were used. Unmodified shoots: no additional modifications were made; modified shoots: a syringe and needle were used to apply a layer of petrolatum to the abaxial surfaces of all leaves to prevent evaporation from the majority of stomata; isolated shoots: shoots were removed from the normal culture medium and inserted into a layer of petrolatum to isolate them from any supply of water. After shoot preparation, the gas exchange system was temporarily turned off, and the culture vessel was quickly substituted for the water-filled vessel that had been used to equilibrate the system at $90 \% \mathrm{RH}$. The system was then restarted, and the dry air flow control manually adjusted to maintain $90 \%$ $\pm 0.4 \%$ RH during the course of the experiment. Typically, this procedure required substantial adjustment only during the first $10 \mathrm{~min}$ and no additional adjustments after 1 to $2 \mathrm{hr}$.

At the completion of each experiment (typically $24 \mathrm{hr}$ ), the entire gas exchange system was transferred to a humidified glove box, shoots were removed, and leaf fresh weight was determined. Leaves were hydrated by placing them in a beaker of water and their leaf area was determined with a Delta $\mathrm{T}$ Area Meter (Decagon Instruments, Pullman, Wash.) while they were between sheets of clear plastic. Leaves were then dried in an oven for 2 days at $80 \mathrm{C}$ for dry weight measurements. The dry weight and water content were also determined for a number of individual shoots taken directly from culture. Observations of abaxial and adaxial leaf surfaces on intact shoots were made at × 200 with a vertically illuminated microscope (BHMJ system; Olympus, New York) using a long working distance $(11 \mathrm{~mm})$ $\times 20$ objective (1-LM546; Olympus). The shoot, vial, and microscope objective were enclosed in a loosely fitting, humidified plastic bag during the observations to prevent plant desiccation and allow flexibility in positioning the leaves.

\section{Results and Discussion}

In all experiments, unmodified shoots exhibited rapid initial reductions in leaf conductance $\left(g_{1}\right)$ followed by more. gradual reductions, reaching relatively stable values of $g_{1}$ by the end of the 24-hr test period (Fig. 3). The three curves for unmodified shoots represent the range of variability observed in the 11 unmodified shoots tested. They are typical in that shoots exhibiting high initial values of $\mathrm{g}_{1}$ (the highest recorded was 700 $\mathrm{mmol} \cdot \mathrm{m}^{-2} \cdot \mathrm{s}^{-1}$ ) also exhibited high final values and relatively slow rates of decline during much of the test period. The variability in shoot size was considerable, ranging from leaf areas of 3.08 to $9.81 \mathrm{~cm}^{2}$, but, after correcting for leaf area, there was no apparent relation between shoot size or morphology and shoot gas exchange characteristics. The substantial reduction in $\mathrm{g}_{1}$, averaging $73 \%$, indicated that the stomata of these shoots were functional. The relatively rapid reduction in $g_{1}$ that was observed in some plants further supports this conclusion.

The apparent reduction in $\mathrm{g}$, over time for unmodified shoots (Fig. 3) could have been due to water contamination in the gas exchange system itself. Evaporation of water derived from the medium or of superficial water on leaf surfaces, for example, would cause overestimation of conductance initially. The rate of water loss from vials containing uncoated media was substantial. No water loss was detected, however, when the me- 


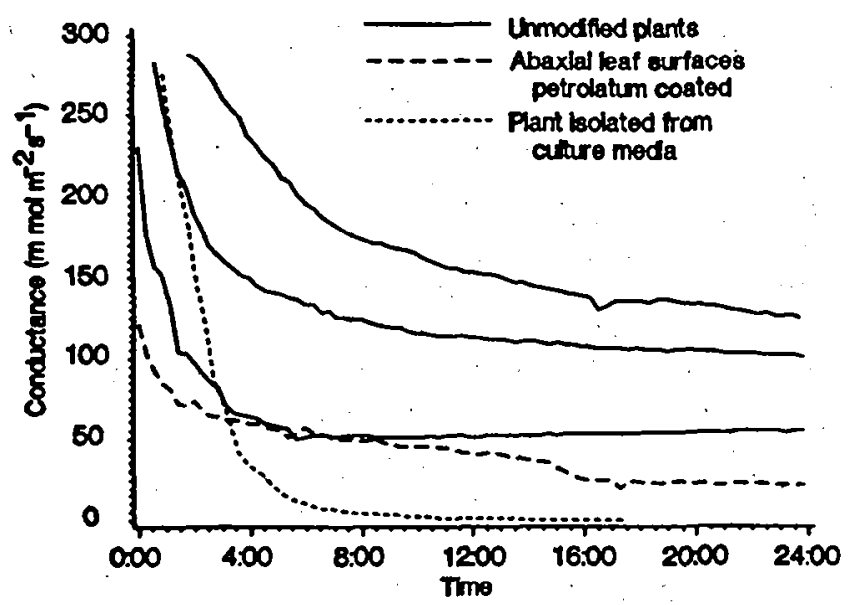

Fig. 3. Leaf conductance over time (hours : minutes) for representative shoots of three experimental treatments (unmodified, abaxial surfaces coated, and isolated from media) in the gas exchange system of Fig. 1. Values of conductance $>300 \mathrm{mmol} \cdot \mathrm{m}^{-2} \cdot \mathrm{s}^{-1}$ are omitted for clarity.

dium was completely covered by petrolatum, indicating that the petrolatum seal was effective. High rates of water loss also occurred initially from wet filter paper placed on the petrolatum, but these dropped to zero after $1 \mathrm{hr}$. Hence, even a substantial quantity of superficial water on the shoot (none was apparent) would have a negligible effect on $g_{1}$ after $1 \mathrm{hr}$. The apparent reduction in stomatal conductance may also have been due to the loss of tissue-derived water and shoot desiccation. Presumably, such desiccation would be associated with visual symptoms of damage, especially if the observed $73 \%$ reduction in apparent $g_{1}$ largely had been a consequence of the desiccation. However, for unmodified shoots, there was no visual evidence of damaged leaves at the completion of each experiment.

Isolated shoots were used to evaluate the maximum impact that loss of tissue-derived water would have on $\mathrm{g}_{1}$, since, for these shoots, all transpired water would be tissue derived. The $\mathrm{g}_{1}$ of isolated shoots exhibited a rapid linear decline during the first 3 to $4 \mathrm{hr}$ of gas exchange (Fig. 3), and, within 12 to $16 \mathrm{hr}$ of the beginning of each experiment, all leaves were wilted, stems were black and brittle, and no water loss could be detected. These tests confirmed that desiccation could cause decreases in $\mathrm{g}$, , but that substantial desiccation would also be associated with visible symptoms of injury. Some desiccation by the end of $24 \mathrm{hr}$ was evident by the lower leaf water content of both isolated and unmodified shoots, compared with that of shoots taken directly from culture (Table 1). However, unmodified shoots lost considerably more water per unit leaf dry weight $(13.6 \mathrm{~g})$ than their initial water content (control, $6.7 \mathrm{~g}$ ), indicating that the major portion of water transpired by unmodified plants was not water lost by desiccation of tissues, but rather was water replaced by uptake from the medium.

In summary, the data presented indicate that the stomata of these tissue-cultured shoots were functional and closed in response to environmental conditions of increased evaporative demand. Evidence of stomatal closure was also found by microscopic examination (Fig. 4). On all leaves observed, stomata were open when shoots were taken directly from tissue culture conditions (Fig. 4, top). For unmodified shoots, stomata were closed after $24 \mathrm{hr}$ in the gas exchange system (Fig. 4, bottom).

It is not possible to distinguish stomatal $\left(\mathrm{g}_{\mathrm{s}}\right)$ from cuticular $\left(g_{c}\right)$ conductance in entire leaves (Ball, 1987), but if all stomata
Table 1. Leaf and shoot water content (grams of water per gram of leaf dry weight) for control shoots (directly from tissue culture) and experimental shoots (after $24 \mathrm{hr}$ in the gas exchange system), and the calculated amount of water lost by experimental shoots during gas exchange measurements.

\begin{tabular}{|c|c|c|c|c|}
\hline \multirow{2}{*}{ Treatment } & \multirow[b]{2}{*}{$\mathrm{N}^{2}$} & \multicolumn{2}{|c|}{$\begin{array}{c}\text { Water contenty } \\
\text { ( } \mathrm{g} \mathrm{H}_{2} \mathrm{O} / \mathrm{g} \text { leaf dry wt) }\end{array}$} & \multirow{2}{*}{$\begin{array}{c}\text { Water loss' } \\
\text { (g } \mathrm{H}_{2} \mathrm{O} / \mathrm{g} \text { leaf dry wt) }\end{array}$} \\
\hline & & Leaf & Shoot & \\
\hline Control & 10 & $3.56 \pm 0.97$ & $.7 \pm 2.2$ & $\ldots x$ \\
\hline $\begin{array}{l}\text { Unmodified } \\
\text { (stem base } \\
\text { in agar) }\end{array}$ & 11 & $2.01 \pm 0.56$ & - & $13.6 \pm 2.0$ \\
\hline $\begin{array}{l}\text { Isolated } \\
\text { (stem base } \\
\text { in petrolatum) }\end{array}$ & 3 & $1.28 \pm 0.32$ & $-\infty$ & $5.6 \pm 2.4$ \\
\hline
\end{tabular}

${ }^{\mathrm{z}}$ Number of individual shoots sampled.

${ }^{\mathrm{y}}$ Mean \pm 1 SD.

${ }^{\mathrm{x}}$ Not applicable.

were fully closed after $24 \mathrm{hr}$ in the gas exchange system, then the minimum $g_{1}$ would represent twice $g_{c}$, since cuticular water loss occurs from both leaf surfaces. Consequently, for the 11 unmodified shoots tested, the range of apparent $\mathrm{g}_{\mathrm{c}}$ was 18 to 64 $\mathrm{mmol} \cdot \mathrm{m}^{-2} \cdot \mathrm{s}^{-1}$. If any water loss occurred from surfaces other than the leaves (i.e., stems) or if stomatal closure on the leaves was not complete, then these values of $g_{c}$ would be overestimates. On hypostomatous leaves, a more reliable method of estimating $\mathrm{g}_{\mathrm{c}}$ (Holmgren et al., 1965) involves prevention of stomatal transpiration by coating abaxial leaf surfaces with a layer of petrolatum, as was done to modified shoots. Microscopic observations indicated that stomata were largely confined to abaxial leaf surfaces, as had been reported by Sutter (1988). The gas exchange behavior (Fig. 3) for the four modified shoots indicated a range of apparent $\mathrm{g}_{\mathrm{c}}$ of 19 to $40 \mathrm{mmol} \cdot \mathrm{m}^{-2} \cdot \mathrm{s}^{-1}$. The upper limit of this range was somewhat less than that observed for unmodified shoots, indicating that some incomplete stomatal closure may have occurred in unmodified shoots. However, the changes in $\mathrm{g}_{1}$ that were exhibited by some of the modified shoots over $24 \mathrm{hr}$ (Fig. 3) also indicated that stomata in other locations, i.e., the margins of the adaxial leaf surface, as observed by Sutter (1988), may have influenced the values of apparent $\mathrm{g}_{\mathrm{c}}$ in modified shoots. Since any stomatal water loss would cause an overestimate of $\mathrm{g}_{\mathrm{c}}$, the range of 18 to 40 $\mathrm{mmol} \cdot \mathrm{m}^{-2} \cdot \mathrm{s}^{-1}$ may be regarded as a maximum estimate for the $\mathrm{g}_{\mathrm{c}}$ of leaves on these shoots. This entire range is less than the value of $g_{c_{1}}$ reported earlier for similar plants, i.e., 83 $\mathrm{mmol} \cdot \mathrm{m}^{-2} \cdot \mathrm{s}^{-1}$ after conversion from the original units (Sutter, 1988), but may be more reliable since it is based on a larger sample of leaf area and more rigorously calibrated methods. The lower portion of this range is also close to the upper bound of the range of $\mathrm{g}_{\mathrm{c}}$ commonly occurring in fully expanded leaves, i.e., 2 to $13 \mathrm{mmol} \cdot \mathrm{m}^{-2} \cdot \mathrm{s}^{-1}$ after conversion from the original units (Nobel, 1974); hence, we conclude that tissue culture conditions do not necessarily result in abnormal cuticular properties, such as uniformly high values of $\mathrm{g}_{\mathrm{c}}$ in apple leaves.

Stresses that are associated with excessive water loss in plants result from an interaction of two independent processes-regulation of water loss and efficient water uptake. In this study, substantial variability between shoots was observed in the rapidity of stomatal closure and in the final value of $g_{1}$ achieved when shoots were exposed to an increase in evaporative demand. Hence, when exposed to an environmental stress, such 

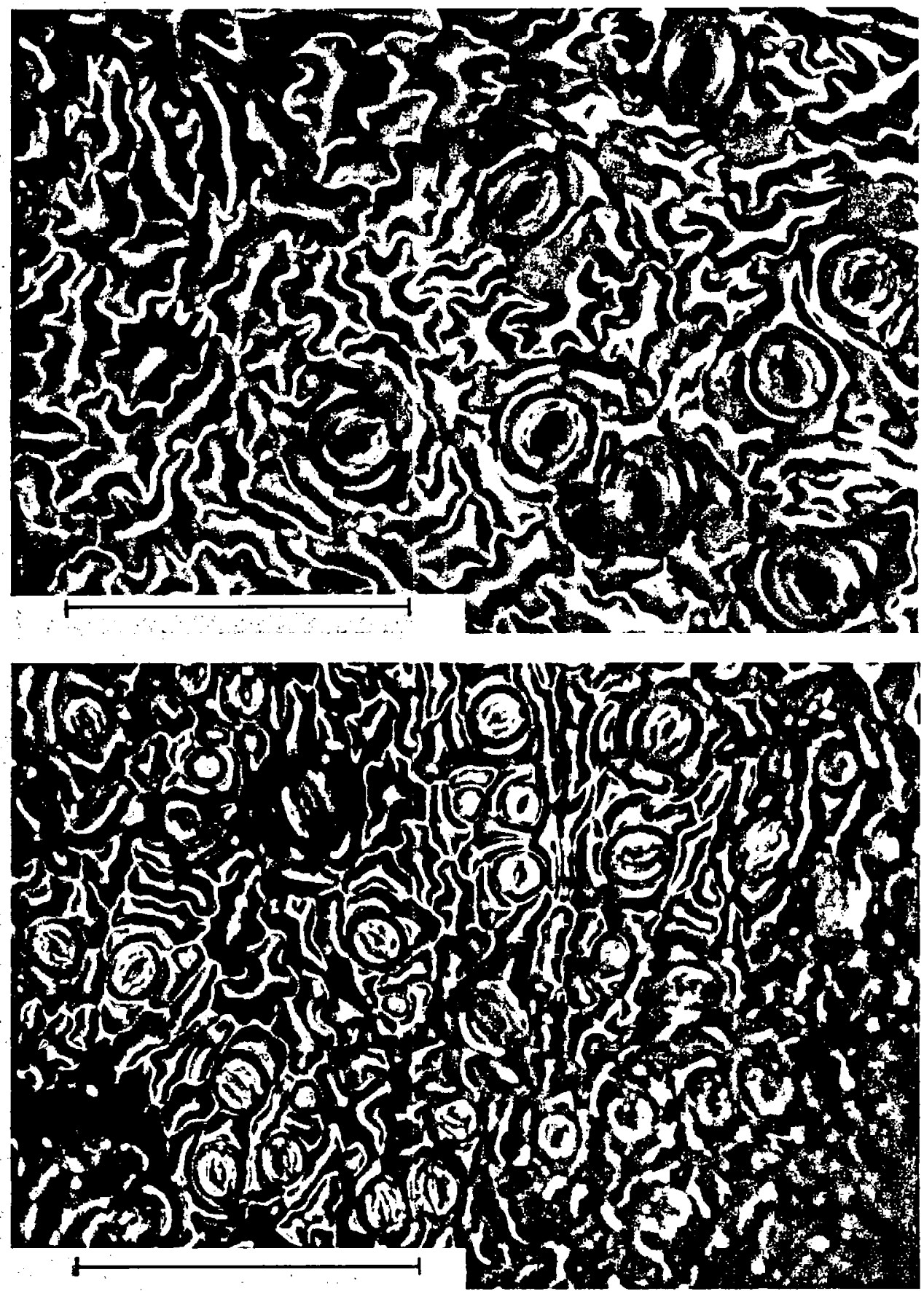

Fig. 4. Micrographs of the abaxial leaf surfaces of shoots. (top) Leaf of shoot taken directly from tissue culture showing open stomata. (bottom) Leaf of shoot after $24 \mathrm{hr}$ in the gas exchange system showing closed stomata. The bar on both micrographs equals $100 \mu \mathrm{m}$.

as removal from culture and transfer to greenhouse conditions, the ability of any individual shoot to restrict its water loss and avoid desiccation may be variable. Some shoots required $>24$ $\mathrm{hr}$ to achieve minimal $\mathrm{g}_{1}$ after being transferred to new environmental conditions. For such shoots, a gradual transition from tissue culture to greenhouse conditions may be necessary. This study has also demonstrated that, despite stomatal closure, unmodified shoots lost an average of twice their water content over $24 \mathrm{hr}$ (Table 1). Presumably, this required water uptake from the medium through the epidermal and cortical cells of the stem. Since these stem tissues may not be specifically differentiated for the radial transport of water, as are the comparable tissues in roots, it is possible that a substantial gradient in water potential was associated with this water movement (Boyer, 1985). Consequently, even low rates of transpiration may have been associated with substantial water stress in the leaves. The occurrence of water stress under gas exchange conditions may account for both the stomatal closure (Fig. 3) and the reduced leaf water content (Table 1) observed in the unmodified shoots of this study. Since the survival of tissue-cultured shoots after removal from culture may depend largely on the balance between water loss and water uptake, factors that enhance the ability of plants to transport water, such as increased length of stem in contact with the media or the presence of roots, may 
be as important to survival as stomatal or cuticular regulation of water loss.

\section{Literature Cited}

Ball, T.J. 1987. Calculations related to gas exchange, p. 445-476. In: E. Zeiger, G.D. Farguhar, and I.R. Cowan (eds.). Stomatal function. Stanford Univ. Press, Stanford, Calif.

Boyer, J.S. 1985. Water transport. Annu. Rev. Plant Physiol. 36:473516.

Brainerd, K.E. and L.H. Fuchigami. 1982. Stomatal functioning of in vitro and greenhouse apple leaves in darkness, mannitol, ABA, and $\mathrm{CO}_{2}$. J. Expt. Bot. 33:388-392.

Brainerd, K.E., L.H. Fuchigami, S. Kwiatkowski, and C.S. Clark. 1981. Leaf anatomy and water stress of aseptically cultured 'Pixy' plum grown under different environments. HortScience 16:173-175.

Fuchigami, L.H., T.Y. Cheng, and A. Soeldner. 1981. Abaxial transpiration and water loss in aseptically cultured plum. J. Amer. Soc. Hort. Sci. 106:519-522.

Holmgren, P., P.G. Jarvis, and M.S. Jarvis. 1965. Resistance to car- bon dioxide and water vapor transfer in leaves of different plant species. Physiol. Plant. 18:557-573.

Linsmaier, E. and F. Skoog. 1965. Organic growth factor requirements of tobacco tissue cultures. Physiol. Plant. 18:100-127.

Nobel, P.S. 1974. Introduction to biophysical plant physiology. Freeman, San Francisco. p. 310

Sutter, E.G. 1988. Stomata! and cuticular water loss from apple, cherry, and sweetgum plants after removal from in vitro culture. J. Amer. Soc. Hort. Sci. 113:234-238.

Sutter, E. and R.W. Langhans. 1982. Formation of epicuticular wax and its effect on water loss in cabbage plants regenerated from shoottip culture. Can. J. Bot. 60:2896-2902.

Wardle, K., P.A. Dixon, and I. Simpkins. 1981. Sodium accumulation by leaves of cauliflower plantlets and the effect of the mode of plant formation. Ann. Bot. 47:653-659.

Wardle, K. and K.C. Short. 1983. Stomatal response of in vitro cultured plantlets. I. Responses in epidermal strips of Chrysanthemum to environmental factors and growth regulators. Biochem. Physiol. Pflanzen. 178:619-624.

J. Amer. Soc. Hort. SCI. 115(3):472-477. 1990.

\title{
Inhibition by $\mathrm{NaCl}$ of $\mathrm{Net} \mathrm{CO}_{2}$ Fixation and Yield of Cucumber
}

\author{
Malcolm C. Drew ${ }^{1}$, Pamela S. Hold, and Geno A. Picchioni ${ }^{3}$ \\ Texas Agricultural Experimental Station, Department of Horticultural Science, Texas A\&M \\ University, College Station, TX 77843-2133
}

Additional index words. greenhouse trials. photosynthesis, salinity, stress, Cucumis sativus

Abstract. Cucumber (Cucumis sativus L. cv. Fidelio) grown in sand culture in the greenhouse was trickle-irrigated with nutrient solution containing 0,10 , or $50 \mathrm{mM} \mathrm{NaCl}$. Gas exchange of Individual leaves was measured by a portable infrared gas analyzer et saturating photosynthetic photon flux. Salt at $10 \mathrm{~mm}$ had no detectable effect on plant performance, but exposure to $50 \mathrm{mM} \mathrm{NaCl}$ caused net $\mathrm{CO}_{2}$ fixation to decline by $33 \%$ and $48 \%$ in the eighth and ninth oldest leaves, respectively. Stomatal conductance and transpiration rate were also reduced $(\approx 50 \%)$ In these leaves. These differences, as well as lower leaf water potentials, were associated with a $60 \%$ reduction in fruit fresh weight. The relationship between net $\mathrm{CO}_{2}$ fixation and intercellular (substomatal) $\mathrm{CO}_{2}$ concentrations was determined for individual, attached leaves of plants with roots exposed to various concentrations of $\mathrm{NaCl}$ in hydroponics. With 50 and $100 \mathrm{~mm} \mathrm{NaCl}$, a nonstomatal contribution to the inhibition of photosynthesis at the chloroplast level was Indicated by strong inhibition of $\mathrm{CO}$, fixation at a saturating $\mathrm{CO}_{2}$ concentration. Salt-induced inhibition of $\mathrm{CO}_{2}$ fixation was associated with accumulation of $\mathrm{Na}+$ and $\mathrm{Cl}-$, and lower $\mathrm{K}+$ in the individual leaves examined.

High productivity of cucumbers in the greenhouse results from optimization of the aerial and rooting environments, with yields between 223 to $446 \mathrm{t} \cdot \mathrm{ha}^{-1}$, compared with $10.7 \mathrm{t} \cdot \mathrm{ha}^{-1}$ under field conditions (Ware and McCollum, 1975). Such heavy yields, combined with higher market prices obtainable out of season, offer advantages to producers located in the southern and southwestern United States, where solar radiation is rarely limiting. However, the quality of water supply in the region is potentially limiting to the productivity of greenhouse cucumbers, a moderately salt-sensitive crop (Gornat et al., 1973; Maas and Hoffman, 1977; Sonnveld and Vogt, 1978; Drews, 1979). The threshold electrical conductivity of the rooting medium of cu-

\footnotetext{
Received for publication 27 June 1988. Texas Agricultural Experiment Station Journal Series TA 23792. We are grateful to DeRuiter Seeds, Columbus, Ohio, for a gift of 'Fidelio' cucumber seed. The cost of publishing this paper was defrayed in part by the payment of page charges. Under postal regulations, this paper therefore must be hereby marked advertisement solely to indicate this fact.

${ }^{1}$ Associate Professor.

${ }^{2}$ Graduate Research Associate.

${ }^{3}$ Graduate Research Assistant.
}

cumbers, above which appreciable declines in growth and yield can be expected, is between 2.5 and $3.0 \mathrm{dS} \cdot \mathrm{m}^{-1}$ (reviewed by Maas and Hoffman, 1977; see also Kazim and Khaliel, 1983; Maas, 1985), and can be as low as 0.8 to $1.6 \mathrm{dS} \cdot \mathrm{m}^{-1}$ (Jones et al., 1989).

Although mechanisms of salt tolerance and salt injury have been examined in numerous crop species (Maas and Nieman, 1978; Wyn Jones, 1981), there is relatively little information available on cucumber. In general, the more-negative osmotic potential of saline irrigation water contributes adversely to plant water relations, and the excess accumulation of specific ions (especially $\mathrm{Na}+$ or $\mathrm{Cl}-$ ) within the leaf mesophyll is a major factor associated with depression of plant, growth (Jennings, 1976; Greenway and Munns, 1980).

Many salt-sensitive species tolerate moderate exposure to salt by the roots' ability to exclude ions from the xylem sap and, hence, the leaves through energy-dependent processes (Läuchli, 1984; Drew and Läuchli, 1985). At higher concentrations of salt, the processes of exclusion are inadequate, and excess $\mathrm{Na}+$ and/or Cl- are transported via the xylem to the shoot (Drew and Dikumwin, 1985; Drew and Läuchli, 1985). Abnormal concentrations of these ions in the cytoplasm have been associated with 